\title{
Perencanaan Drainase Berbasis Eco-Technology ditinjau dari Migrasi Ular \\ (Studi Kasus: Suaka Rhino Sumatera, Taman Nasional Way Kambas)
}

\author{
Eco-Technology Based on Drainage Planning \\ In Terms of Snake Migration \\ (Case Study: Sumatran Rhino Sanctuary, Way Kambas National Park)
}

\author{
AHMAD HERISON ${ }^{1}$, YUDA ROMDANIA $^{1}$, ENDRO P. WAHONO ${ }^{1}$, M. YUSRIZAL FAHRI² \\ ${ }^{1}$ Dosen Jurusan Teknik Sipil Universitas Lampung, Bandar Lampung Jl. Prof. Sumantri Brojonegoro No.1 Bandar Lampung 35145 \\ ${ }^{2}$ Mahasiswa Jurusan Teknik Sipil Universitas Lampung, Bandar Lampung Jl. Prof. Sumantri Brojonegoro No.1 Bandar Lampung \\ 35145 \\ Email: ahmadherison@yahoo.com
}

\begin{abstract}
Way Kambas National Park (TNWK) is one of the conservation areas in Lampung Province. The National Park functions to protect, preserve various kinds of animals and conservation. Design based on EcoTechnology is an absolute requirement for the sustainability of the region. This study aims to plan EcoTechnology-based drainage from road construction in the Sumatra Rhino Sanctuary (SRS), Way Kambas National Park, with snake objects. Every infrastructure development, such as drainage, must pay attention to the lives of wild animals such as snakes. Planning starts with calculating hydrological analysis to produce a debit plan with a rational method. Analysis of snake migration is done to determine the behavior and migration of snakes. Based on the calculation results there is no flood point from the planning of cross-section D1-D8 with the width of the channel width $(b)=20 \mathrm{~cm}$, water depth $(h)=14.47$ $\mathrm{cm}$, peak width $(B)=220 \mathrm{~cm}$, cross-section $=10^{\circ}$ and cross-section material used is soil. With the drainage concept, the migration of snakes from one span to another is not disturbed to maintain the balance of the natural ecosystem. The conclusion is that the drainage design obtained is getting sloping, so the drainage conditions are better and friendly to snakes.
\end{abstract}

Keywords: Eco-Technology, drainage, conservation, Way Kambas National Park, snake migration

\begin{abstract}
ABSTRAK
Taman Nasional Way Kambas (TNWK) merupakan satu diantara kawasan konservasi yang berada di Provinsi Lampung. Taman Nasional berfungsi untuk melindungi, melestarikan berbagai macam satwa dan konservasi. Desain yang berbasis Eco-Technology merupakan syarat mutlak untuk keberlanjutan kawasan itu. Penelitian ini bertujuan untuk merencanakan drainase berbasis Eco-Technology dari suatu pembangunan jalan di Suaka Rhino Sumatera (SRS), Taman Nasional Way Kambas dengan objek ular. Setiap pembangunan Infrastruktur seperti drainase harus memperhatikan kehidupan satwa liar seperti ular. Perencanaan dimulai dengan melakukan perhitungan analisis hidrologi untuk dapat menghasilkan debit rencana dengan metode rasional. Analisis migrasi ular dilakukan untuk mengetahui perilaku dan migrasi ular. Berdasarkan hasil perhitungan tidak terdapat titik banjir dari perencanaan penampang D1D8 dengan ukuran lebar dasar saluran $(b)=20 \mathrm{~cm}$, kedalaman air $(h)=14,47 \mathrm{~cm}$, lebar puncak $(B)=220$ $\mathrm{cm}$, kemiringan penampang $=10^{\circ}$ dan bahan penampang yang digunakan adalah tanah. Dengan adanya konsep drainase tersebut, migrasi ular dari bentang satu ke bentang lainnya tidak terganggu sehingga dapat menjaga keseimbangan ekosistem alam. Kesimpulannya adalah desain drainase yang didapat makin landai, maka kondisi drainase makin baik dan ramah terhadap ular.
\end{abstract}

Kata kunci: Eco-Technology, drainase, konservasi, Taman Nasional Way Kambas, migrasi ular 


\section{PENDAHULUAN}

\subsection{Latar Belakang}

Sebaran flora dan fauna di Indonesia termasuk dalam kategori yang luas. Dengan jenis flora sebesar $10 \%$ dunia tumbuh di Indonesia dan berbagai fauna seperti burung, mamalia, ikan, reptil dan amfibi masing-masing sebesar $17 \%$, $12 \%, 25 \%$ dan $16 \%{ }^{(1)}$. Secara ekologis, flora dan fauna tersebut memiliki peranan penting dalam kelangsungan proses-proses ekologi untuk menjaga keseimbangan ekosistem. Rusak atau hilangnya salah satu komponen dalam ekosistem akan menyebabkan gangguan terhadap ekosistem serta berkurangnya kualitas lingkungan.

Rekayasa ekologi merupakan ilmu ekologi sebagai dasar untuk perencanaan dengan membatasi intervensi manusia dalam memberikan solusi dan manajemen ekosistem yang berkelanjutan $^{(2-5)}$. Desain yang berekologi berfokus pada proses alam, sosial, dan budaya dengan melihat desain sebagai proses yang berulang yang sebagian besar dibentuk oleh hubungan timbal balik antara manusia dan ekosistem $^{(6)}$. Hal ini sangat perlu dilakukan oleh engineer di Indonesia dalam melakukan desain sehingga dapat menjaga keseimbangan alam dan kelangsungan hidup manusia.

Aplikasi Eco-Technology atau rekayasa ekologi banyak ragamnya. Contohnya meliputi pengolahan air limbah, restorasi ekosistem, dan langkah-langkah mitigasi untuk mengurangi terbunuhnya satwa(7). Adapun aplikasi tersebut belum diterapkan di Kawasan Taman Nasional Way Kambas.

Taman Nasional Way Kambas (TNWK) merupakan salah satu kawasan pelestarian alam yang ada di Provinsi Lampung yang memiliki peran untuk melindungi berbagai satwa dari ancaman kepunahan. Di Kawasan TNWK terdapat penangkaran badak yang bernama Suaka Rhino Sumatera (SRS) dan badak tersebut merupakan salah satu satwa yang termasuk kedalam kategori terancam punah (critically endangered $)^{(8)}$

Menurut Subakir (Kepala Balai TNWK), kondisi Suaka Rhino Sumatera saat ini kurang memadai. Oleh karena itu, diperlukan perluasan area yang semula $100 \mathrm{Ha}$ menjadi $250 \mathrm{Ha}$ yang ditetapkan oleh Direktur Jenderal KSDAE melalui SK Dirjen No.SK.307/KSDAE-KKH/2016(9). Akibat perluasan tersebut, diperlukan pekerjaan infrastruktur di antaranya jalan, drainase, dan pembatas kandang badak.

Hal tersebut masih berbeda dengan kondisi infrastruktur yang ada saat ini belum ramah lingkungan. Artinya desain yang ada dibuat tidak berdasarkan pada faktor-faktor ekologi dan Undang-Undang Republik Indonesia Nomor 5 Tahun 1990(10), khususnya drainase. Adapun kondisi drainasenya yaitu memutus koloni satwa yang pada umumnya hidup di tanah/darat khususnya satwa reptil ular untuk bermigrasi dari bentang satu ke bentang yang lainnya.

Dalam proses perencanaan infrastruktur ekologi atau ramah lingkungan harus didasarkan pada perencanaan prinsip multi disiplin, multi level, integritas, dan keberlanjutan ${ }^{(10)}$. Pembangunan infrastruktur keberlanjutan ini memiliki tujuan yang sangat penting yaitu untuk menjaga keseimbangan alam dan kesejahteraan manusia khususnya untuk generasi masa depan ${ }^{(11)}$.

\subsection{Tujuan Penelitian}

Tujuan dari penelitian ini adalah untuk merencanakan drainase berbasis Eco-Technology dari suatu pembangunan jalan di Suaka Rhino Sumatera (SRS), Taman Nasional Way Kambas dengan objek ular. Hasil dari analisis migrasi ular maka didapatkan kemiringan dan bahan drainase yang sesuai sehingga tidak memutus migrasi ular tersebut.

\section{BAHAN DAN METODE}

\subsection{Daerah Penelitian}

Lokasi penelitian terletak di Taman Nasional Way Kambas yang berada di Kabupaten Lampung Timur, Provinsi Lampung. Suaka Rhino Sumatera merupakan bagian dari Taman Nasional Way Kambas yang memiliki tujuan khusus untuk penangkaran dan pengembangbiakan badak Sumatera. Peta lokasi ditunjukan pada Gambar 1.

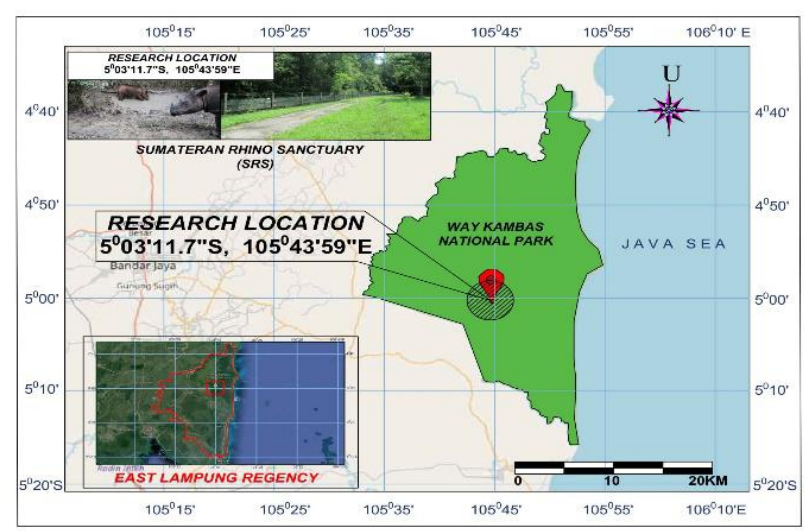

Gambar 1. Peta Lokasi penelitian di Suaka Rhino Sumatra, Taman Nasional Way Kambas

\subsection{Metode Penelitian}

Metode penelitian merupakan langkah-langkah untuk menghimpun data yang dibutuhkan dalam

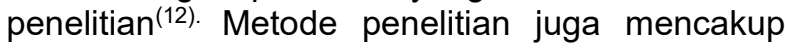
tahapan demi tahapan untuk melakukan sebuah penelitian $^{(12)}$. Desain yang akan dilakukan dengan melihat aspek teknis dan aspek lingkungan. Data 
teknis dan data lingkungan, akan dianalisis dalam sebuah perencanaan yang memperhatikan ekosistem yang ada, sehingga perencanaan ramah lingkungan yang berkelanjutan. Untuk menunjang penelitian ini, dibutuhkan data primer yang diperoleh dari lapangan dan data sekunder yang diperoleh dari instansi terkait. Lihat Tabel 1 dan Tabel 2.

Tabel 1. Data Primer

\begin{tabular}{|c|c|c|}
\hline No & $\begin{array}{l}\text { Teknik } \\
\text { Pengambilan Data }\end{array}$ & Kegunaan Data \\
\hline 1. & Dokumentasi & $\begin{array}{l}\text { Model visual berupa } \\
\text { foto diperlukan dalam } \\
\text { memperkuat fakta } \\
\text { yang ada mengenai } \\
\text { kondisi di lapangan }\end{array}$ \\
\hline 2. & Data Topografi & $\begin{array}{l}\text { Mengetahui elevasi } \\
\text { kontur dan panjang } \\
\text { saluran drainase }\end{array}$ \\
\hline 3. & GPS & $\begin{array}{l}\text { Menentukan titik } \\
\text { lokasi drainase }\end{array}$ \\
\hline 4. & $\begin{array}{l}\text { Sketsa } \\
\text { kawasan/peta }\end{array}$ & $\begin{array}{l}\text { Menggambarkan } \\
\text { daerah penelitian }\end{array}$ \\
\hline
\end{tabular}

Tabel 2. Data Sekunder

\begin{tabular}{|c|c|c|}
\hline No & Judul Data & Kegunaan \\
\hline 1. & $\begin{array}{l}\text { Data Curah } \\
\text { Hujan }\end{array}$ & $\begin{array}{l}\text { Untuk mengetahui berapa } \\
\text { jumlah hujan yang turun } \\
\text { di lokasi }\end{array}$ \\
\hline 2. & $\begin{array}{l}\text { Data perilaku } \\
\text { dan migrasi } \\
\text { ular }\end{array}$ & $\begin{array}{l}\text { Mengetahui perilaku dan } \\
\text { migrasi ular }\end{array}$ \\
\hline 3. & $\begin{array}{l}\text { Data peraturan } \\
\text { Taman } \\
\text { Nasional }\end{array}$ & $\begin{array}{l}\text { Mengetahui hal-hal yang } \\
\text { dilarang dalam kawasan } \\
\text { konservasi }\end{array}$ \\
\hline
\end{tabular}

\subsection{Peralatan}

Peralatan yang digunakan untuk pengambilan data primer, lihat Tabel 3.

Tabel 3. Peralatan yang dibutuhkan

\begin{tabular}{|c|c|c|}
\hline No & $\begin{array}{c}\text { Alat dan } \\
\text { Bahan }\end{array}$ & Fungsi \\
\hline 1. & GPS & Tracking lokasi \\
\hline 2. & Kamera & Sebagai alat dokumentasi \\
\hline 3. & Laptop & $\begin{array}{l}\text { Sebagai alat untuk mengolah } \\
\text { data }\end{array}$ \\
\hline 4. & Meteran & Mengukur panjang \\
\hline 5. & Alat tulis & $\begin{array}{l}\text { Mencatat hasil data di } \\
\text { lapangan }\end{array}$ \\
\hline 6. & Waterpass & $\begin{array}{l}\text { Mengukur atau menentukan } \\
\text { sebuah benda atau garis } \\
\text { dalam posisi rata baik } \\
\text { pengukuran secara vertikal } \\
\text { maupun horizontal }\end{array}$ \\
\hline 7. & $\begin{array}{l}\text { Total } \\
\text { Station }\end{array}$ & $\begin{array}{l}\text { Mengukur jarak dan sudut } \\
\text { (vertikal dan horizontal) }\end{array}$ \\
\hline
\end{tabular}

\subsection{Tahapan Penelitian}

Adapun tahap-tahap penelitian adalah sebagai berikut:

1. Mengumpulkan data primer dan data sekunder;

2. Analisis hidrologi yang dimulai dari:

a. Menghitung hujan harian maksimum;

b. Analisa data hujan yang hilang;

c. Uji konsistensi data menggunakan metode kurva massa ganda, dikarenakan jumlah stasiun hujan $>3$ buah;

d. Menghitung curah hujan rerata menggunakan metode Thiessen;

e. Analisis frekuensi curah hujan;

f. Uji sebaran

g. Menghitung curah hujan rencana;

h. Menghitung intensitas curah hujan;

i. Koefisien Pengaliran;

j. Menghitung debit rencana kala ulang 5 tahun;

3. Analisis perilaku dan migrasi ular;

4. Membandingkan debit dengan analisis perilaku dan migrasi ular untuk mendapatkan penampang yang sesuai;

5. Desain penampang drainase menggunakan program sketchup.

\section{HASIL DAN PEMBAHASAN}

\subsection{Analisis Hidrologi}

Analisis hidrologi merupakan tahap awal dalam perhitungan perencanaan drainase untuk mendapatkan besarnya debit banjir rencana. Perhitungan ini menggunakan data hujan harian pada stasiun Braja Selebah, Braja Sakti, Braja Sari dan Way Jepara yang berada di sekitar Kawasan SRS yang kemudian diolah sehingga menjadi curah hujan rencana.

\subsection{Data Curah Hujan}

Data curah hujan yang diperoleh berasal dari Balai BWS Mesuji Sekampung yaitu stasiun hujan Braja Selebah, Braja Sakti, Braja Sari, dan Way Jepara dari tahun 2007-2016.

\subsection{Analitis Intensitas Curah Hujan}

Analisis perhitungan intensitas curah hujan menggunakan rumus mononobe, seperti pada persamaan di bawah ini :

$$
\mathrm{I}=\frac{R_{24}}{24}\left(\frac{24}{t}\right) \wedge 2 / 3
$$

Keterangan

$$
\begin{array}{ll}
\mathrm{I} & \text { : Intensitas curah hujan (mm/jam) } \\
\mathrm{t} & \text { : Durasi curah hujan (jam) } \\
\mathrm{R}_{24} & \text { : Curah hujan rencana dalam suatu periode ulang }
\end{array}
$$

Hasil perhitungan intensitas curah hujan dapat dilihat pada Tabel 4. 


\subsection{Koefisien Pengaliran}

Berdasarkan penggunaan tata guna lahan di wilayah SRS, digunakan berbagai macam tata guna lahan. Hal ini digunakan sebagai koefisien pengaliran gabungan untuk perhitungan debit rencananya. Sehingga untuk koefisien pengaliran, deskripsi lahannya yaitu jalan, bangunan, parkiran dan lahan terbuka dan dapat dilihat pada Tabel 5.

Tabel 4. Perhitungan intensitas hujan

\begin{tabular}{ccc}
\hline No & $\begin{array}{c}\text { Periode Ulang } \\
\text { (Tahun) }\end{array}$ & Intensitas Hujan (mm/jam) \\
\hline 1 & 2 & 93,8541 \\
2 & 5 & 129,9161 \\
3 & 10 & 154,6133 \\
4 & 25 & 186,7031 \\
5 & 50 & 211,0883 \\
6 & 100 & 236,2498 \\
\hline
\end{tabular}

Tabel 5. Perhitungan Koefisien Pengaliran

\begin{tabular}{llll}
\hline $\begin{array}{l}\text { Penggunaan } \\
\text { Lahan }\end{array}$ & $\begin{array}{l}\text { Koefisien } \\
(\mathrm{C})\end{array}$ & $\begin{array}{l}\text { Luas/1000 } \\
\left(\mathrm{m}^{2}\right)\end{array}$ & $\mathrm{C} \times \mathrm{A}$ \\
\hline Bangunan & 0,95 & 0,188 & 0,1786 \\
Jalan & 0,95 & 33,9476 & 32,2502 \\
Parkiran & 0,70 & 0,2016 & 0,1411 \\
Lahan & 0,40 & 1789,6907 & 715,8763 \\
Kosong & & & \\
(Hutan) & & & \\
Jumlah & & 1824,0279 & 748,4462 \\
\hline
\end{tabular}

\subsection{Perhitungan Debit Rencana}

Perhitungan debit rencana merupakan metode yang dianjurkan oleh Kementerian Pekerjaan Umum tahun 2014(13). Perhitungan dengan menggunakan metode rasional merupakan acuan nilai debit rencana yang digunakan serta merupakan nilai debit rasional yang sesuai untuk DAS $<500 \mathrm{Ha}$, maka pemilihan debit rasional digunakan dalam mendesain penampang drainase dan pengecekan kapasitas saluran karena cukup ideal dan ekonomis. Perhitungan debit rencana, seperti rumus di bawah ini:

$$
\mathrm{Q}=0,2778 \times C \times \mathrm{I} \times \mathrm{A} .
$$

\section{Keterangan}

Q : Debit Puncak limpasan permukaan ( $\mathrm{m}^{3} /$ detik)

$C$ : Angka pengaliran

I : Intensitas curah hujan ( $\mathrm{mm} / \mathrm{jam})$

A : Luas daerah pengaliran $\left(\mathrm{Km}^{2}\right)$

Hasil perhitungan Debit Rencana (Q) kala ulang 5 tahun dari tiap Section D1-D8 dapat dilihat pada Tabel 6 .

\subsection{Perencanaan Penampang Drainase}

Pada perencanaan penampang drainase dilakukan analisis terhadap perilaku dan migrasi ular. Analisis yang dilakukan adalah terhadap bahan dan kemiringan penampang drainase yang ramah terhadap satwa ular, serta dapat dilalui oleh ular. Perencanaan bahan penampang didasarkan pada Undang-Undang Nomor 5 Tahun 1990 tentang Konservasi Sumber Daya Alam Hayati dan Ekosistemnya. Adapun hasil dari analisis dapat dilihat pada Tabel 7 .

Tabel 6. Perhitungan Debit Rencana dengan Metode Rasional

\begin{tabular}{cccccc}
\hline No & $\begin{array}{c}\text { Kode } \\
\text { Drainase }\end{array}$ & $\mathrm{C}$ & $\begin{array}{c}\mathrm{I} \\
(\mathrm{mm} / \mathrm{jam})\end{array}$ & $\begin{array}{c}\mathrm{A} \\
\left(\mathrm{Km}^{2}\right)\end{array}$ & $\begin{array}{c}\mathrm{Q} \\
\left(\mathrm{m}^{3} / \mathrm{s}\right)\end{array}$ \\
\hline 1 & D1-D2 & 0,4103 & 129,9160 & 0,0064 & 0,0947 \\
2 & D2-D3 & 0,4103 & 129,5474 & 0,0039 & 0,0575 \\
3 & D3-D4 & 0,4103 & 203,3241 & 0,0037 & 0,0857 \\
4 & D4-D5 & 0,4103 & 69,2731 & 0,0063 & 0,0497 \\
5 & D5-D6 & 0,4103 & 56,5122 & 0,0028 & 0,0180 \\
6 & D6-D7 & 0,4103 & 73,2710 & 0,0083 & 0,0693 \\
7 & D7-D8 & 0,4103 & 92,6376 & 0,0047 & 0,0496 \\
8 & D1-D8 & 0,4103 & 104,9640 & 0,0034 & 0,0406 \\
\hline
\end{tabular}

Tabel 7. Analisis Bahan dan Kemiringan Penampang

\begin{tabular}{|c|c|c|c|c|c|}
\hline No & $\begin{array}{l}\text { Kemiringan } \\
\text { Penampang }\end{array}$ & Tanah & Rumput & Batu & Kaca \\
\hline 1 & $10^{\circ}$ & Sesuai & Sesuai & Sesuai & $\begin{array}{l}\text { Tidak } \\
\text { sesuai }\end{array}$ \\
\hline 2 & $20^{\circ}$ & Sesuai & Sesuai & Sesuai & $\begin{array}{l}\text { Tidak } \\
\text { sesuai }\end{array}$ \\
\hline 3 & $30^{\circ}$ & Sesuai & Sesuai & Sesuai & $\begin{array}{l}\text { Tidak } \\
\text { sesuai }\end{array}$ \\
\hline 4 & $40^{\circ}$ & Sesuai & Sesuai & Sesuai & $\begin{array}{l}\text { Tidak } \\
\text { sesuai }\end{array}$ \\
\hline 5 & $50^{\circ}$ & $\begin{array}{l}\text { Kurang } \\
\text { sesuai }\end{array}$ & $\begin{array}{l}\text { Kurang } \\
\text { sesuai }\end{array}$ & $\begin{array}{l}\text { Kurang } \\
\text { sesuai }\end{array}$ & $\begin{array}{l}\text { Tidak } \\
\text { sesuai }\end{array}$ \\
\hline 6 & $60^{\circ}$ & $\begin{array}{l}\text { Kurang } \\
\text { sesuai }\end{array}$ & $\begin{array}{l}\text { Kurang } \\
\text { sesuai }\end{array}$ & $\begin{array}{l}\text { Kurang } \\
\text { sesuai }\end{array}$ & $\begin{array}{l}\text { Tidak } \\
\text { sesuai }\end{array}$ \\
\hline 7 & $70^{\circ}$ & $\begin{array}{l}\text { Tidak } \\
\text { sesuai }\end{array}$ & $\begin{array}{l}\text { Tidak } \\
\text { sesuai }\end{array}$ & $\begin{array}{l}\text { Tidak } \\
\text { sesuai }\end{array}$ & $\begin{array}{l}\text { Tidak } \\
\text { sesuai }\end{array}$ \\
\hline
\end{tabular}

Keterangan :

1). Sesuai: Bahan ramah lingkungan dan mudah untuk meresapkan air, kemiringan penampang drainase dapat dilewati satwa ular.

2). Kurang sesuai: Bahan ramah lingkungan tetapi kemiringan penampang drainase kurang landai untuk dapat dilewati satwa ular.

3). Tidak sesuai: Bahan tidak ramah lingkungan (kaca) dan kemiringan penampang drainase tidak dapat dilewati satwa ular.

Berdasarkan analisis di atas, peneliti menggunakan bahan berupa tanah dan kemiringan penampang $10^{\circ}$ dikarenakan tanah merupakan habitat asli satwa ular dan kemiringan paling landai serta dapat dilalui satwa ular. Perhitungan kesesuaian debit dengan bahan dan Panjang (kemiringan) penampang yang direncanakan menggunakan program Hec-rass, sehingga didapatkan lebar dasar saluran $(b)=20$ $\mathrm{cm}$, kedalaman air $(\mathrm{h})=14,47 \mathrm{~cm}$, lebar puncak (B) $=220 \mathrm{~cm}$, tinggi jagaan $=3,16 \mathrm{~cm}$, kemiringan $10^{\circ}$ dan bahan berupa tanah. Ilustrasi ditunjukan pada Gambar 2. 


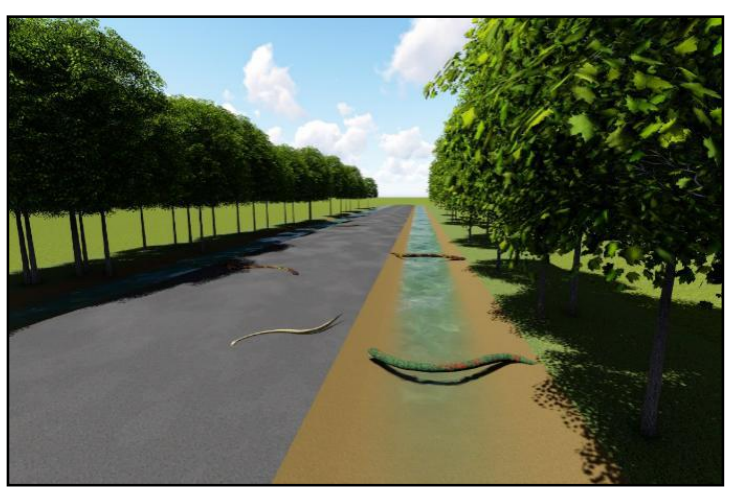

Gambar 2. Penampang Drainase

\subsection{Perbandingan Desain Drainase Eco Technology dan non Eco-Technology}

Beberapa perbandingan desain EcoTechnology dan non Eco-Technology, dapat dilhat pada Tabel 8.

\subsection{Perbandingan Biaya}

Hasil Rencana Anggaran Biaya (RAB) yang direncanakan lebih murah dibandingkan dengan existing dilapangan, dapat dilihat pada Tabel 9. Konstruksi drainase menggunakan bahan tanah lebih murah dibandingkan rumput, batu dan kaca.

Tabel 8. Perbandingan Desain

\begin{tabular}{cll}
\hline No & Eco-Technology & Non Eco-Technology \\
\hline 1 & Ramah & Tidak ramah \\
& lingkungan & lingkungan \\
2 & Konservasi air & Tidak konservasi air \\
3 & Mengurangi banjir & Mudah banjir \\
4 & $\begin{array}{l}\text { Biaya relatif } \\
\text { murah }\end{array}$ & Biaya relatif mahal \\
5 & $\begin{array}{l}\text { Tidak } \\
\text { mengganggu } \\
\text { bentang alam }\end{array}$ & Mengganggu \\
& bentang alam \\
\hline
\end{tabular}

Tabel 9. Rencana Anggaran Biaya (RAB)/Meter

\begin{tabular}{cccccc}
\hline \multirow{2}{*}{$\begin{array}{c}\text { Kemiringan } \\
\text { Penampang }\end{array}$} & \multicolumn{5}{c}{ Harga (Rp) } \\
& Tanah & Rumput & Batu & Kaca & Existing \\
\hline $10^{\circ}$ & $14.321,51$ & $20.321,51$ & $62.037,65$ & $32.321,51$ & \\
$20^{\circ}$ & $24.750,77$ & $30.750,77$ & $72.466,91$ & $42.750,77$ & \\
$30^{\circ}$ & $32.863,05$ & $38,863,05$ & $80.579,19$ & $50.863,05$ & \\
$40^{\circ}$ & $37.848,25$ & $43.848,25$ & $85.564,39$ & $55.848,25$ & \\
$50^{\circ}$ & $39.241,84$ & $45.241,84$ & $86.957,98$ & $57.241,84$ & $53.058,53$ \\
$60^{\circ}$ & $37.009,83$ & $43.009,83$ & $84.725,97$ & $55.009,83$ & \\
$70^{\circ}$ & $31.520,45$ & $37.520,45$ & $79.236,59$ & $49.520,45$ & \\
$80^{\circ}$ & $23.515,80$ & $29.515,80$ & $71.231,94$ & $41.515,80$ & \\
$90^{\circ}$ & $13.998,60$ & $19.998,60$ & $61.714,74$ & $31.998,60$ & \\
\hline
\end{tabular}

\section{KESIMPULAN}

Berdasarkan seluruh hasil tahapan yang telah dilakukan pada perencanaan drainase berwawasan lingkungan dapat disimpulkan bahwa desain drainase yang didapat makin landai, maka kondisi drainase makin baik dan ramah terhadap ular. Beberapa hasil perhitungan yang didapat sebagai berikut.

1. Lebar dasar saluran $(b)=20 \mathrm{~cm}$, kedalaman air (h) $=14,47 \mathrm{~cm}$, lebar puncak $(B)=220 \mathrm{~cm}$, tinggi jagaan $=3,16 \mathrm{~cm}$ dan kemiringan penampang yang sesuai dengan migrasi ular adalah $10^{\circ}$.

2. Konsep Eco-Technology sangat cocok untuk diterapkan di Kawasan Konservasi seperti Taman Nasional karena ramah terhadap satwa dan lingkungan sehingga dapat menjaga keseimbangan dan keberlanjutan ekosistem alam.

3. Perbandingan biaya yang paling murah adalah menggunakan bahan tanah.

\section{PERSANTUNAN}

Ucapan terima kasih kami sampaikan kepada Kepala Balai Taman Nasional Way Kambas dan tim Yayasan Badak Indonesia (YABI) yang telah memberi izin serta mendukung pelaksanaan observasi lapangan hingga terlaksananya penelitian ini.

\section{DAFTAR PUSTAKA}

1. Bappenas. (1993). Biodiversity Action Plan for Indonesia. Final Draft.

2. Matlock, M. D., Osborn, G. S., Hession, W. C., Kenimer, A. L., \& Storm, D. E. (2001). Ecological engineering: a rationale for standardized curriculum and professional certification in the United States. Ecological Engineering, 17(4), 403-409. 
3. Mitsch, W.J., Jorgensen, S.E. (2003). Ecological Engineering and Ecosystem Restoration. Jhon Willey \& Sons, Inc., New York, $411 \mathrm{pp}$.

4. Mitsch, W.J., (2012). What is Ecological Engineering. Ecol. Eng, 45, 5-12.

5. Odum, H. T., \& Odum, B. (2003). Concepts and methods of ecological engineering. Ecological Engineering, 20(5), 339-361.

6. Yang, B., \& Ming-Han, L. I. (2010). Ecological engineering in a new town development: Drainage design in The Woodlands, Texas. Ecological Engineering, 36(12), 16391650.

7. Bergen, S. D., Bolton, S. M., \& Fridley, J. L. (2001). Design principles for ecological engineering. Ecological Engineering, 18(2), 201-210.

8. [IUCN]. International Union for Conservation of Nature and Natural Resources. (2008). IUCN
Red List of Threatened Species. http://www.iucnredlist.org [10 September 2017].

9. SK Dirjen No.SK.307/KSDAE-KKH/2016 tentang Penetapan Perluasan Area Kandang Badak Taman Nasional Way Kambas.

10. Republik Indonesia, (1990). Undang-undang Nomor 5 Tahun 1990 tentang Konservasi Sumberdaya Alam Hayati dan Ekosistemnya. Sekretariat Negara Republik Indonesia, Jakarta.

11.Brüll, A., van Bohemen, H., Costanza, R., Mitsch, W. J., van den Boomen, R., Chaudhuri, N., ... \& Schönborn, A. (2011). Benefits of ecological engineering practices. Procedia Environmental Sciences, 9, 16-20.

12. Arikunto, S. (2006). Prosedur Penelitian: Suatu Pendekatan Praktik. Jakarta: Rineka Cipta.

13. Peraturan Menteri Pekerjaan Umum Nomor 12/PRT/M/2014 tentang Penyelenggaraan Sistem Drainase Perkotaan 